\title{
Synthesis of $\mathrm{NdSc}_{3}\left(\mathrm{BO}_{3}\right)_{4}$ single crystals and
}

\section{study of its structure properties}

Evgeniy V. Eremin ${ }^{a, b, c}$, Maxim S. Pavlovskiy ${ }^{a, b}$, Irina A. Gudim ${ }^{a}$, Vladislav Temerov ${ }^{a}$, Maxim Molokeev $^{a, b}$, Nikita D. Andryushin ${ }^{a, b,}{ }^{*}$, and Evgeniy V. Bogdanov ${ }^{a, d}$

${ }^{a}$ Kirensky Institute of Physics, Federal Research Center KSC SB RAS, Krasnoyarsk 660036 Russia

${ }^{\mathrm{b}}$ Siberian Federal University, Krasnoyarsk 660041, Russia

${ }^{c}$ Siberian State University of Science and Technologies, Krasnoyarsk 660037 Russia

${ }^{\mathrm{d}}$ Institute of Engineering Systems and Energetics, Krasnoyarsk State Agrarian University, Krasnoyarsk, 660049 Russia

*Corresponding e-mail: and@iph.krasn.ru 


\begin{abstract}
Using the group method, single crystals of $\mathrm{NdSc}_{3}\left(\mathrm{BO}_{3}\right)_{4}$ are grown from a melt solution and $\mathrm{X}$-ray structural studies are performed. It is shown that at room temperature the $\operatorname{NdSc}_{3}\left(\mathrm{BO}_{3}\right)_{4}$ crystal has a huntite-type structure with space group $P 3{ }_{1} 21$. The temperature dependence of the heat capacity shows anomalous behaviour at $\mathrm{T}=504 \pm 1 \mathrm{~K}$. This anomaly corresponds to a structural phase transition from $R 32$ to $P 3_{1} 21$. It is known that a similar transition occurs in $\mathrm{RFe}_{3}\left(\mathrm{BO}_{3}\right)_{4}$ crystals; an anomaly in the specific heat is also observed. Theoretical calculations are carried out from the first principles of the lattice dynamics of the crystal under study in a high-symmetry phase with the $R 32$ space group. An unstable (soft) mode in the boundary point of Brillouin zone was found. It was determined that this structural instability is responsible for the structural displacement-type phase transition $R 32 \rightarrow P 3_{1} 21$.
\end{abstract}

\title{
Keywords: phase transition, crystal growth, lattice dynamics, multiferroic
}

\section{INTRODUCTION}

In recent years, after the coexistence of magnetic and electrical ordering in some materials was discovered, an intensive search has been carried out for new materials with a strong interconnection between the magnetic and electrical subsystems. [1-6] One promising group of compounds is the rare-earth oxyborates with the structure of the natural mineral huntite $\mathrm{RM}_{3}\left(\mathrm{BO}_{3}\right)_{4}(\mathrm{R}=\mathrm{Y}, \mathrm{La}-\mathrm{Lu} ; \mathrm{M}=\mathrm{Fe}, \mathrm{Al}, \mathrm{Cr}, \mathrm{Ga}, \mathrm{Sc})$. These materials are currently being intensively studied by many research groups. [7-13] It has been established that hydroxyborates with two magnetic subsystems (ferroborates $\mathrm{RFe}_{3}\left(\mathrm{BO}_{3}\right)_{4}$ ) belong to the class of multiferroics. [7, 9, 13]

When studying the magnetoelectric effect in huntite-like crystals, the crystal structure of the object under study plays an important role, since the magnetoelectric effect is very 
sensitive to the local environment of the rare-earth ion. It is known that rare-earth ferroborates with the huntite structure $\mathrm{RFe}_{3}\left(\mathrm{BO}_{3}\right)_{4}$ at high temperatures have a trigonal structure, which belongs to the $R 32$ space group. In compounds with a large ionic radius $(\mathrm{R}=$ $\mathrm{La}, \mathrm{Ce}, \mathrm{Pr}, \mathrm{Nd}, \mathrm{Sm}$ ), this structure remains unchanged even at the lowest temperatures, while in compounds with a smaller ionic radius $(\mathrm{R}=\mathrm{Eu}, \mathrm{Gd}, \mathrm{Tb}, \mathrm{Dy}, \mathrm{Ho}, \mathrm{Er})$, there is a structural phase transition $R 32 \rightarrow P 3_{1} 21$, the temperature of which increases with decreasing ionic radius. With such a transition, anomalies are observed in the temperature dependences of the dielectric properties, heat capacity and thermal expansion. [8] Changing the space group also alters the symmetry of the local environment of the rare-earth ion in the ligand field from $D 3$ (for $R 32$ ) to $C 2$ (for $\left.P 3_{1} 21\right)$.

Recently, it was discovered that aluminoborates $\mathrm{RAl}_{3}\left(\mathrm{BO}_{3}\right)_{4}$, which have previously attracted attention mainly due to their optical and magneto-optical properties, [14-17] demonstrate gigantic magnetoelectric polarization values. [18-20] These compounds in the entire temperature range have a crystalline structure with the $R 32$ space group. For example, in $\mathrm{HoAl}_{3}\left(\mathrm{BO}_{3}\right)_{4}$, the magnetoelectric polarisation value is quite large among the known magnetoelectrics $\Delta P_{\mathrm{ab}}\left(B_{\mathrm{b}}\right)=-5240 \mu \mathrm{C} / \mathrm{m}^{2}$ (at $\mathrm{T}=5 \mathrm{~K}$ in a field of $9 \mathrm{~T}$ ), [12] which is several times larger than the known maximum values of the magnetoelectric polarisation in ferroborates $\mathrm{RFe}_{3}\left(\mathrm{BO}_{3}\right)_{4}$. An increase in the magnetoelectric effect is also observed when replacing ions in $\mathrm{HoFe}_{3}\left(\mathrm{BO}_{3}\right)_{4}$ from $\mathrm{Fe}^{3+}$ to $\mathrm{Ga}^{3+}$. [13]

Considering that replacing the magnetic subsystem $(\mathrm{Fe})$ in $\mathrm{RM}_{3}\left(\mathrm{BO}_{3}\right)_{4}$ with a nonmagnetic subsystem ( $\mathrm{Al}, \mathrm{Ga})$ causes the magnetoelectric effect to reach gigantic values, it seems promising to explore other subclasses of hydroxyborates with the structure of the huntite with one magnetic subsystem; for example, the rare-earth scandoborates $\mathrm{RSc}_{3}\left(\mathrm{BO}_{3}\right)_{4}$. However, before investigating the magnetoelectric effect, it is necessary to understand which structural state $\mathrm{NdSc}_{3}\left(\mathrm{BO}_{3}\right)_{4}$ exists in. 
This study describes the method of growing $\mathrm{NdSc}_{3}\left(\mathrm{BO}_{3}\right)_{4}$ single crystals from a bismuth molybdate melt solution and demonstrates the results of X-ray structural and calorimetric studies, as well as calculations from first principles.

\section{MATERIALS AND METHODS}

A bismuth trimolybdate based melt solution was used for growing the single crystals. The investigated melt solution system can be expressed in the quasi-binary form:

$89 \%$ weight $\left[\mathrm{Bi}_{2} \mathrm{Mo}_{3} \mathrm{O}_{12}+3 \mathrm{Li}_{2} \mathrm{O}_{3}+2 \mathrm{~B}_{2} \mathrm{O}_{3}+0,1 \mathrm{Nd}_{2} \mathrm{O}_{3}\right]+11 \%$ weight $\mathrm{NdSc}_{3}\left(\mathrm{BO}_{3}\right)_{4}$

The $150 \mathrm{~g}$ melt solution weights were prepared at $\mathrm{T}=1000^{\circ} \mathrm{C}$ by sequential melting of the corresponding oxides $\left(\mathrm{Bi}_{2} \mathrm{O}_{3}\right.$ (reagent grade), $\mathrm{MoO}_{3}$ (analytical grade), $\mathrm{Li}_{2} \mathrm{CO}_{3}$ (analytical grade), $\mathrm{B}_{2} \mathrm{O}_{3}$ (special-purity grade), $\mathrm{Sc}_{2} \mathrm{O}_{3}$ (special-purity grade) and $\mathrm{Sm}_{2} \mathrm{O}_{3}$ (SmO-L) (domestic reagents)) in a platinum cylindrical crucible with a $50 \mathrm{~mm}$ diameter and a $60 \mathrm{~mm}$ height. Then, the crucible with the melt solution was placed in a furnace with a temperature gradient, the vertical component of which at $\mathrm{T}=1000{ }^{\circ} \mathrm{C}$ decreases at a rate of $2-3{ }^{\circ} \mathrm{C} / \mathrm{cm}$ from the bottom to the top of the crucible.

The stability regions of $\mathrm{NdSc}_{3}\left(\mathrm{BO}_{3}\right)_{4}$ crystals, as well as the corresponding ratios of melt solution components, were determined by direct phase sensing. After melt solution homogenisation at $\mathrm{T}=1080^{\circ} \mathrm{C}$ for $24 \mathrm{~h}$, the temperature was reduced to the expected saturation temperature $\left(\mathrm{T}_{\text {sat }}\right)$ and a platinum wire crystal carrier of $4 \mathrm{~mm}$ in diameter was immersed into the melt solution. After $1-2 \mathrm{~h}$, the crystal carrier was withdrawn and the nucleation on it was estimated. The probings were then performed with the temperature decreasing down to $\mathrm{T} \approx 850{ }^{\circ} \mathrm{C}$ with a step of $10-20{ }^{\circ} \mathrm{C}$ without overheating the solution. Thereafter, the saturation temperature was determined with an accuracy of $\pm 2{ }^{\circ} \mathrm{C}$ using test crystals. For this melt solution, the saturation temperature was $980{ }^{\circ} \mathrm{C}$. 
The lower boundary of the $\mathrm{NdSc}_{3}\left(\mathrm{BO}_{3}\right)_{4}$ metastability zone is defined as the maximum supercooling, where spontaneous crystals do not form on the superheated rod for $24 \mathrm{~h}$ (i.e. the rod was immersed into the melt solution at the homogenisation temperature before decreasing the temperature).

To obtain $\mathrm{NdSc}_{3}\left(\mathrm{BO}_{3}\right)_{4}$ crystal seeds, the method of limiting the number of seeds by nucleation in a thin layer of melt solution was used. After determining the parameters of crystallisation, in the melt solution at a homogenisation temperature, the rod was immersed and rotated at a speed of $40 \mathrm{rpm}$. After $2 \mathrm{~h}$, the temperature of the melt solution decreased by $5-7{ }^{\circ} \mathrm{C}$ below the saturation temperature. After a further $2 \mathrm{~h}$, the rod was lifted into the colder zone of the furnace chamber (the temperature was $10-15^{\circ} \mathrm{C}$ below the saturation temperature). In this case, a small number of seeds was formed in the thin layer of the melt solution enveloping the rod. Their number was small, since in a small volume of the remaining melt solution, the concentration of crystal-forming oxides fell sharply. The nucleation took place within $1 \mathrm{~h}$. The rod was then again immersed into the melt solution and seeds were grown during the day. After that, the rod was removed from the furnace. The remains of the melt solution were removed by boiling in a $20 \%$ aqueous solution of nitric acid. The grown seed crystals were removed from the rod and used for growing large crystals.

\section{Seed growth of the crystals}

Four high-quality seeds smaller than $1 \mathrm{~mm}$ in size were mounted on a rod. The crystal carrier was suspended above the flux at $T=1000{ }^{\circ} \mathrm{C}$. Next, the temperature was decreased to $T=T_{\text {sat }}+7^{\circ} \mathrm{C}$, the crystal holder with seeds was immersed into the flux to a depth of $25-30$ $\mathrm{mm}$ and the rotation with a speed of $30 \mathrm{rpm}$ and a reversal period of $1 \mathrm{~min}$ was switched on. After $15 \mathrm{~min}$, the temperature was decreased to $T=T_{\mathrm{sat}}-5^{\circ} \mathrm{C}$. Then, the temperature was decreased by $1-3{ }^{\circ} \mathrm{C}$ per day, according to a special program, so that the crystal growth rate 
did not exceed $0.5 \mathrm{~mm}$ per day. The growth process finished in 9-13 days. The crystal carrier was lifted above the flux and cooled to room temperature at a rate of not more than $100{ }^{\circ} \mathrm{C} / \mathrm{h}$. The grown crystals were up to $5 \mathrm{~mm}$ in size, which is sufficient for studying their physical properties. No spontaneous formation and foreign phases were observed (Figure 1).

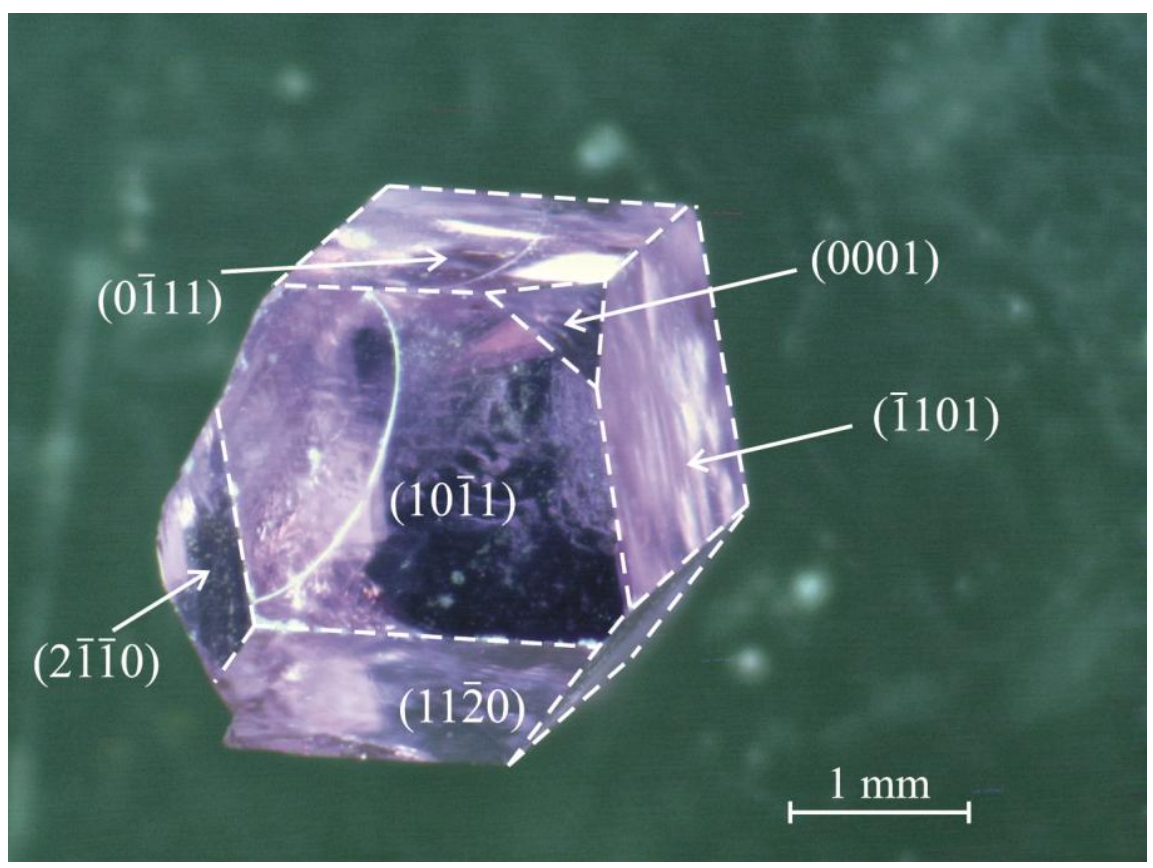

Figure 1. The $\mathrm{NdSc}_{3}\left(\mathrm{BO}_{3}\right)_{4}$ grown crystal.

The X-ray single crystal data from $\mathrm{NdSc}_{3}\left(\mathrm{BO}_{3}\right)_{4}$ was obtained using a SMART APEX II diffractometer (Mo $\mathrm{K}_{\alpha}, \lambda=0.7106 \AA$ ) at room temperature (Krasnoyarsk Regional Center of Research Equipment of Federal Research Center «Krasnoyarsk Science Center SB RAS»). The matrix of orientation and cell parameters were calculated and refined by 6416 reflections. The main information regarding crystal data, data collection and refinement is given in Table 1.

The X-ray measurements of the $\mathrm{NdSc}_{3}\left(\mathrm{BO}_{3}\right)_{4}$ crystal were measured with the exposure time of $10 \mathrm{~s}$ on each frame. Each new frame was obtained by crystal rotation along the $\omega$ axis by $0.5^{\circ}$ at the fixed $\varphi$ angle. The $\omega$ value was increased from 0 to $182^{\circ} .364$ frames were measured at each fixed $\varphi$ equal to 0,120 and $240^{\circ}$. After that, the intensities of the reflections 
were integrated via APEXII software from Bruker. Space group P3121 was defined by analysis of the extinction rules and intensity statistics obtained from all reflections.

Multiscan absorption correction of the reflection intensities was performed using APEXII software. Next, the intensities of equivalent reflections were averaged. The structure of $\mathrm{NdScAl}_{3}\left(\mathrm{BO}_{3}\right)_{4}$ was solved by direct methods using the SHELXS program. [21] The coordinates of all atoms were determined (Table 2). The structural refinement was carried out by least-squares minimisation in SHELXL97. [22] The thermal parameters of all ions were refined isotropically. Two twin domains were observed because the Flack parameter [23] after refinement was equal to $0.83(3)$; therefore, we refined the twin domain ratio Left:Right (Table 1). The crystal structure is presented in Figure 2, with the main bond lengths given in Table 3. The crystallographic data are deposited in the Cambridge Crystallographic Data Centre (CSD \#1950589). The data can be downloaded from the website www.ccdc.cam.ac.uk/data_request/cif.

Calorimetric studies were performed using differential scanning microcalorimetry. [24] The measurements were carried out in a wide range of temperatures of $120-600 \mathrm{~K}$ at a rate of 8$16 \mathrm{~K} / \mathrm{min}$ on samples with mass of $\sim 0.1 \mathrm{~g}$.

Table 1. Crystallographic data and main parameters of processing and refinement of $\mathrm{NdSc}\left(\mathrm{BO}_{3}\right)_{4}$

\begin{tabular}{|c|c|}
\hline \multicolumn{2}{|c|}{ Crystal Data } \\
\hline chemical formula & $\mathrm{NdSc}_{3}\left(\mathrm{BO}_{3}\right)_{4}$ \\
\hline$M_{r}$ & 514.36 \\
\hline space group, $Z$ & $P 3_{1} 21,3$ \\
\hline$a,(\AA)$ & $9.7766(8)$ \\
\hline$c,(\AA)$ & $7.9306(6)$ \\
\hline$V,\left(\AA^{3}\right)$ & $656.47(9)$ \\
\hline$D_{x}, \mathrm{Mg} / \mathrm{m}^{3}$ & 3.903 \\
\hline$\mu, \mathrm{mm}^{-1}$ & 8.133 \\
\hline size & $0.3 \times 0.2 \times 0.1$ \\
\hline & \\
\hline wavelength & $\mathrm{MoK}_{\alpha}, \lambda=0.7106 \AA$ \\
\hline measured reflections & 6416 \\
\hline
\end{tabular}




\begin{tabular}{|c|c|}
\hline independent reflections & 1206 \\
\hline reflections with $I>2 \sigma(I)$ & 1015 \\
\hline absorption correction & multiscan \\
\hline$R_{\text {int }}$ & 0.030 \\
\hline $2 \theta_{\max }\left({ }^{\circ}\right)$ & 59.54 \\
\hline$h$ & $-13 \rightarrow 13$ \\
\hline$k$ & $-13 \rightarrow 13$ \\
\hline$l$ & $-10 \rightarrow 10$ \\
\hline \multicolumn{2}{|c|}{} \\
\hline$R\left[F^{2}>2\left(F^{2}\right)\right]$ & 0.0192 \\
\hline$w R\left(F^{2}\right)$ & 0.0758 \\
\hline$S$ & 0.900 \\
\hline weight & $\mathrm{w}=1 /\left[\sigma^{2}\left(\mathrm{~F}_{\mathrm{o}}{ }^{2}\right)+(0.0632 \mathrm{P})^{2}+0.0559 \mathrm{P}\right]$ where \\
\hline $\mathrm{P}=\left(\mathrm{F}_{\mathrm{o}}^{2}+2 \mathrm{~F}_{\mathrm{c}}{ }^{2}\right) / 3$ \\
\hline Twin domain ratio & $0.84(3): 0.16(3)$ \\
\hline number parameters/restraints & $43 / 0$ \\
\hline$(\Delta / \sigma)_{\max }$ & $<0.001$ \\
\hline$\Delta \rho_{\max } \mathrm{e} / \AA^{3}$ & 0.87 \\
\hline$\Delta \rho_{\min }, \mathrm{e} / \AA^{3}$ & -0.782 \\
\hline $\begin{array}{c}\AA^{3} \\
\text { coeffinction correction }\end{array}$ & $0.031(2)$ \\
\hline
\end{tabular}

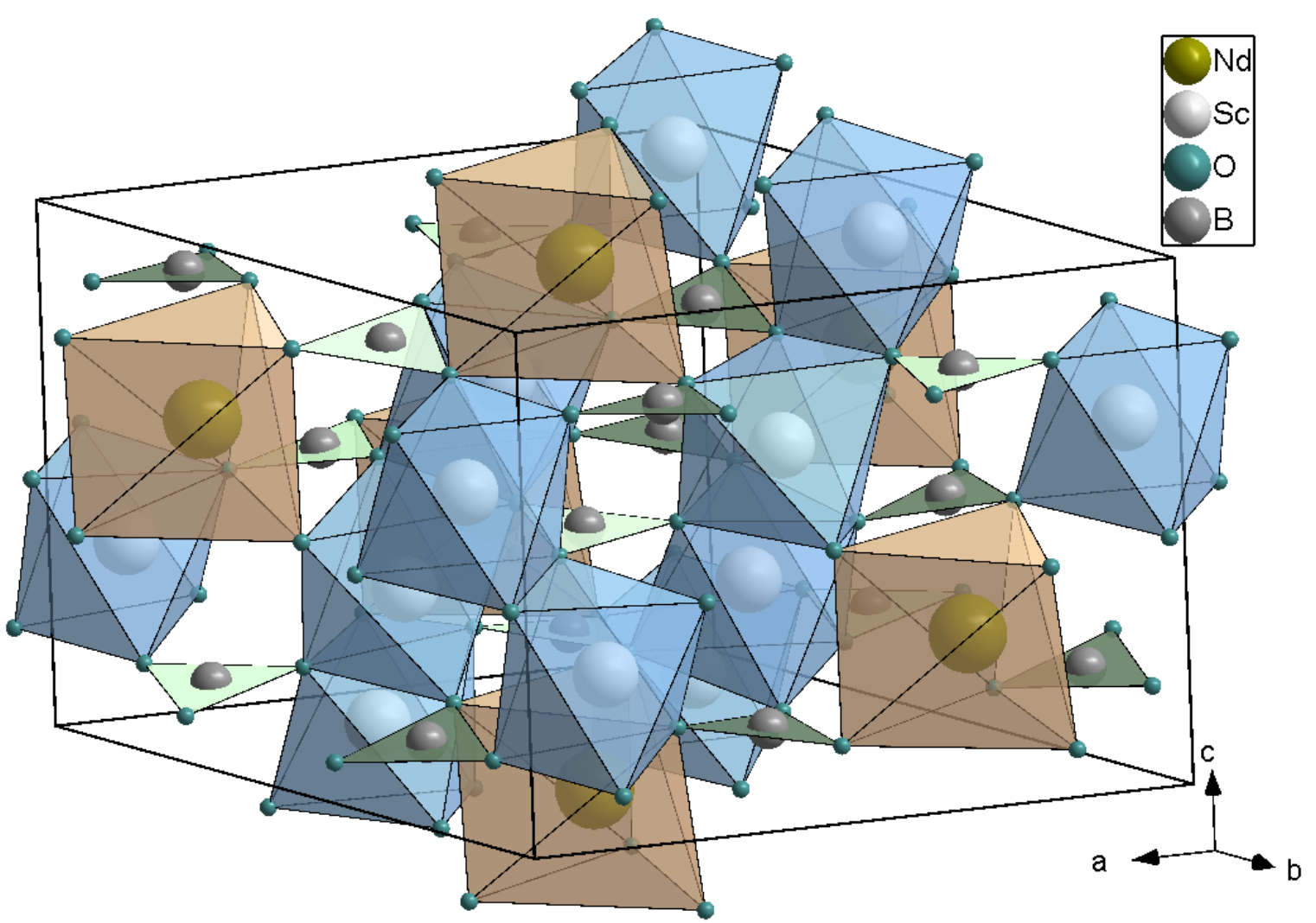

Figure 2. Crystal structure of $\mathrm{NdSc}_{3}\left(\mathrm{BO}_{3}\right)_{4}$. 
Table 2. Fractional atomic coordinates and isotropic or equivalent isotropic displacement parameters $\left(\AA^{2}\right)$. Calculated lattice parameters: $a=9.8479 \AA, c=8.0053 \AA$.

\begin{tabular}{|c|c|c|c|c|c|c|}
\hline Atom & $\begin{array}{c}\text { Wyck. } \\
\text { pos. }\end{array}$ & & $x$ & $y$ & $z$ & $U_{\text {iso }}$ \\
\hline $\mathrm{Nd}$ & $3 a$ & $\begin{array}{l}\exp \\
\text { calc }\end{array}$ & $\begin{array}{c}0.666894(16) \\
0.6656\end{array}$ & $\begin{array}{c}0.666894(16) \\
0.6656\end{array}$ & $\begin{array}{l}0 \\
0\end{array}$ & $0.0076(2)$ \\
\hline Sc1 & $3 a$ & $\begin{array}{l}\text { exp } \\
\text { calc }\end{array}$ & $\begin{array}{c}0.11740(12) \\
0.1173\end{array}$ & $\begin{array}{c}0.11740(12) \\
0.1173\end{array}$ & $\begin{array}{l}0 \\
0\end{array}$ & $0.0070(3)$ \\
\hline $\mathrm{Sc} 2$ & $6 c$ & $\begin{array}{l}\exp \\
\text { calc }\end{array}$ & \begin{tabular}{|c|}
$0.78957(11)$ \\
0.7905
\end{tabular} & $\begin{array}{c}0.45316(11) \\
0.4537\end{array}$ & $\begin{array}{c}0.34475(8) \\
0.3459\end{array}$ & $0.0074(2)$ \\
\hline O1 & $3 b$ & $\begin{array}{l}\text { exp } \\
\text { calc }\end{array}$ & $\begin{array}{l}0 \\
0\end{array}$ & $\begin{array}{c}0.9208(3) \\
0.9209\end{array}$ & $\begin{array}{l}1 / 6 \\
1 / 6\end{array}$ & $0.0172(7)$ \\
\hline $\mathrm{O} 2$ & $6 c$ & $\begin{array}{l}\exp \\
\text { calc }\end{array}$ & $\begin{array}{c}0.4199(3) \\
0.4202\end{array}$ & $\begin{array}{c}0.7242(2) \\
0.7226\end{array}$ & $\begin{array}{c}0.1282(3) \\
0.1254\end{array}$ & $0.0138(5)$ \\
\hline $\mathrm{O} 3$ & $6 c$ & $\begin{array}{l}\exp \\
\text { calc }\end{array}$ & $\begin{array}{c}0.8803(3) \\
0.8787\end{array}$ & $\begin{array}{c}0.6913(3) \\
0.6908\end{array}$ & $\begin{array}{c}0.8240(4) \\
0.8236\end{array}$ & $0.0127(6)$ \\
\hline $\mathrm{O} 4$ & $6 c$ & $\begin{array}{l}\text { exp } \\
\text { calc }\end{array}$ & $\begin{array}{c}0.8575(4) \\
0.8574\end{array}$ & $\begin{array}{c}0.6423(3) \\
0.6425\end{array}$ & $\begin{array}{c}0.1845(4) \\
0.1848\end{array}$ & $0.0123(6)$ \\
\hline O5 & $6 c$ & $\begin{array}{l}\exp \\
\text { calc }\end{array}$ & $\begin{array}{c}0.4716(5) \\
0.4718\end{array}$ & $\begin{array}{c}0.1409(5) \\
0.1415\end{array}$ & $\begin{array}{c}0.8425(2) \\
0.8421\end{array}$ & $0.0094(8)$ \\
\hline O6 & $3 b$ & $\begin{array}{l}\text { exp } \\
\text { calc }\end{array}$ & $\begin{array}{c}0.1919(5) \\
0.1914\end{array}$ & $\begin{array}{l}0 \\
0\end{array}$ & $\begin{array}{l}5 / 6 \\
5 / 6\end{array}$ & $0.0101(9)$ \\
\hline $\mathrm{O} 7$ & $6 c$ & $\begin{array}{l}\exp \\
\text { calc }\end{array}$ & $\begin{array}{c}0.4718(3) \\
0.4708\end{array}$ & $\begin{array}{c}0.4685(3) \\
0.4695\end{array}$ & $\begin{array}{c}0.8154(4) \\
0.8150\end{array}$ & $0.0125(6)$ \\
\hline B1 & $3 b$ & $\begin{array}{l}\text { exp } \\
\text { calc }\end{array}$ & $\begin{array}{c}0.3318(4) \\
0.3320\end{array}$ & $\begin{array}{l}0 \\
0\end{array}$ & $\begin{array}{l}5 / 6 \\
5 / 6\end{array}$ & 0.0104 (18) \\
\hline B2 & $6 c$ & $\begin{array}{l}\text { exp } \\
\text { calc }\end{array}$ & $\begin{array}{c}0.5488(5) \\
0.5487\end{array}$ & $\begin{array}{c}0.8729(5) \\
0.8715\end{array}$ & $\begin{array}{c}0.1516(4) \\
0.1506\end{array}$ & $0.0111(10)$ \\
\hline B3 & $3 b$ & $\begin{array}{l}\exp \\
\text { calc }\end{array}$ & $\begin{array}{l}0 \\
0\end{array}$ & $\begin{array}{c}0.7811(6) \\
0.7801\end{array}$ & $\begin{array}{l}1 / 6 \\
1 / 6\end{array}$ & $0.0118(12)$ \\
\hline
\end{tabular}

Table 3. Bond lengths $(\AA)$ of $\mathrm{NdSc}_{3}\left(\mathrm{BO}_{3}\right)_{4}$

\begin{tabular}{|c|c|c|c|}
\hline $\mathrm{Nd}-\mathrm{O} 7^{\mathrm{i}}$ & $2.418(3)$ & $\mathrm{Sc} 2-\mathrm{O}^{\mathrm{iv}}$ & $2.122(3)$ \\
\hline $\mathrm{Nd}-\mathrm{O}^{\mathrm{ii}}$ & $2.418(3)$ & $\mathrm{Sc} 2-\mathrm{O} 2^{\mathrm{xiV}}$ & $2.134(2)$ \\
\hline $\mathrm{Nd}-\mathrm{O}^{11}$ & $2.421(3)$ & $\mathrm{Sc} 2-\mathrm{O}^{\mathrm{xV}}$ & $2.1489(19)$ \\
\hline $\mathrm{Nd}-\mathrm{O} 3^{\mathrm{i}}$ & $2.421(3)$ & $\mathrm{B} 3-\mathrm{O} 1$ & $1.366(7)$ \\
\hline $\mathrm{Nd}-\mathrm{O} 4$ & $2.474(3)$ & $\mathrm{B} 2-\mathrm{O} 2$ & $1.381(5)$ \\
\hline $\mathrm{Nd}-\mathrm{O} 4^{\text {iii }}$ & $2.474(3)$ & $\mathrm{B} 2^{\mathrm{ii}}-\mathrm{O} 3$ & $1.371(5)$ \\
\hline $\mathrm{Nd}-\mathrm{O} 2$ & $2.921(2)$ & $\mathrm{B} 3^{\mathrm{xx}}-\mathrm{O} 4$ & $1.383(4)$ \\
\hline $\mathrm{Nd}-\mathrm{O} 2^{\text {iii }}$ & $2.921(2)$ & $\mathrm{B} 1-\mathrm{O} 5$ & $1.374(5)$ \\
\hline $\mathrm{Sc} 1-\mathrm{O} 3^{\mathrm{iv}}$ & $2.058(3)$ & $\mathrm{B} 1-\mathrm{O} 6$ & $1.368(6)$ \\
\hline $\mathrm{Sc} 1-\mathrm{O} 3^{\mathrm{V}}$ & $2.058(3)$ & $\mathrm{B} 2^{\mathrm{xx} 111}-\mathrm{O} 7$ & $1.368(4)$ \\
\hline
\end{tabular}




\begin{tabular}{|c|c|c|c|}
\hline $\mathrm{Sc} 1-\mathrm{O}^{1}$ & $2.105(3)$ & $\mathrm{B} 1-\mathrm{O}^{\mathrm{xxIV}}$ & $1.374(5)$ \\
\hline $\mathrm{Sc} 1-\mathrm{O}^{\mathrm{Vi}}$ & $2.105(3)$ & $\mathrm{B} 2-\mathrm{O}^{\mathrm{xxV}}$ & $1.368(4)$ \\
\hline $\mathrm{Sc} 1-\mathrm{O} 1^{\mathrm{Vii}}$ & $2.134(2)$ & $\mathrm{B} 2-\mathrm{O}^{\mathrm{ii}}$ & $1.372(5)$ \\
\hline $\mathrm{Sc} 1-\mathrm{O} 1^{\mathrm{vii1}}$ & $2.134(2)$ & $\mathrm{B} 3-\mathrm{O} 4^{\mathrm{xix}}$ & $1.383(4)$ \\
\hline $\mathrm{Sc} 2-\mathrm{O} 4$ & $2.061(3)$ & $\mathrm{B} 3-\mathrm{O}^{\mathrm{xxv1}}$ & $1.383(4)$ \\
\hline $\mathrm{Sc} 2-\mathrm{O} 7^{\mathrm{xii1}}$ & $2.083(3)$ & & \\
\hline $\mathrm{Sc} 2-\mathrm{O} 5^{\mathrm{xiii}}$ & $2.118(3)$ & & \\
\hline
\end{tabular}

Note: Symmetry codes: (i) $x, y, z-1$; (ii) $y, x,-z+1$; (iii) $y, x,-z$; (iv) $-y+1, x-y, z-2 / 3$; (v) $x-y$, $-y+1,-z+2 / 3$; (vi) $-y, x-y, z-2 / 3$; (vii) $-x+y-1,-x, z-1 / 3$; (viii) $x, y-1, z$; (ix) $-x+y,-x, z-1 / 3$; (x) $y, x-y, z+1 / 3$; (xi) $-y+1, x-y, z+1 / 3$; (xii) $-x+y,-x+1, z-1 / 3$; (xiii) $-x+y+1,-x+1, z-1 / 3$; (xiv) $x+1,-x+y,-z+1 / 3$; (xv) $x-y+1,-y+1,-z+2 / 3$; (xvi) $-x+y+1,-x+1, z+2 / 3$; (xvii) $x, y+1, z$; (xviii) $y, x-y+1, z+1 / 3$; (xix) $-x+1,-x+y+1,-z+1 / 3$; (xx) $x, y, z+1$; (xxi) $x+1, y, z$; (xxii) $-x+y,-x$, $z+2 / 3$; (xxiii) $-x+y,-x+1, z+2 / 3$; (xxiv) $x-y,-y,-z+5 / 3$; (xxv) $-y+1, x-y+1, z-2 / 3$; (xxvi) $x-1, y$, $z$.

\section{RESULTS AND DISCUSSION}

The crystal structure of $\mathrm{NdSc}_{3}\left(\mathrm{BO}_{3}\right)_{4}$ was refined in the $P 3_{1} 21$ space group, which is similar to the model described in [25]. Unfortunately, this $P 3_{1} 21$ model contradicts the $P 321$ model suggested for $\mathrm{NdSc}_{3}\left(\mathrm{BO}_{3}\right)_{4}$ by authors. [26] We tried to refine model P321 using our data, but $\mathrm{R}_{\mathrm{Bragg}}$ factor increased almost five times (up to $10.02 \%$ ) and some thermal parameters became negative while others became very large, which is unusual. Therefore, we suggest that $P 321$ model is not valid. It should be noted that $P 3_{1} 21$ differs from $P 321$ by the absence of 00L reflections with L not equal to 3n (n - integer value except zero). Authors [26] have reported that they observed $00 \mathrm{~L}$ reflections $\mathrm{L}=2 \mathrm{n}+1$ with $\mathrm{I}>3 \operatorname{sig}(\mathrm{I})$, i.e., they proved that $P 3{ }_{1} 21$ model is invalid, but $P 321$ is acceptable. However, checking CIF file that was attached to the Supporting Information revealed that (001) reflection has a module of structural intensity $8.56+/-15.43$, i.e., I is much less that sig(I) and even much less than 3sig(I). All other reflections: (002); (004); (005); (007); (008); (0010); (0011) have $6.52+/-$ $19.30 ; 15.14+/-20.74 ; 1.20+/-13.60 ; 13.47+/-12.96 ; 8.58+/-25.25 ; 39.01+/-27.98 ; 3.00$ +/- 14.17, respectively, i.e, again all (I) values are much less than $3 \operatorname{sig}(\mathrm{I})$ and they could not be considered as observable. In this case the authors should try to refine crystal structure in $P 3{ }_{1} 21$ model also, which they did not, in addition to not comparing the models. Therefore, we can conclude that $P 321$ could be incorrectly chosen and assume that our model $P 3_{1} 21$ is 
more reliable. In addition, the $P 3{ }_{1} 21$ model has only one $\mathrm{Nd}^{3+}$, two $\mathrm{Sc}^{3+}$ and three $\mathrm{B}^{3+}$ ions in the asymmetric part of the unit cell, but P321 has more ions in the asymmetric part: two $\mathrm{Nd}^{3+}$, two $\mathrm{Sc}^{3+}$ and four $\mathrm{B}^{3+}$ ions. Thus, $P 3_{1} 21$ uses a smaller number of refined parameters and is generally speaking more symmetric.

The neodymium scandoborate $\mathrm{NdSc}_{3}\left(\mathrm{BO}_{3}\right)_{4}$ has the $P 3_{1} 21$ structure at room temperature. However, it is known that all the isostructural compounds $\mathrm{RFe}_{3}\left(\mathrm{BO}_{3}\right)_{4}, \mathrm{RAl}_{3}\left(\mathrm{BO}_{3}\right)_{4}$ and $\mathrm{RGa}_{3}\left(\mathrm{BO}_{3}\right)_{4}$ at high temperatures have $R 32$ structure. [8, 12, 13] This suggests that with increasing temperature, starting from the room temperature, one can expect a rearrangement of the crystal structure from $P 3{ }_{1} 21$ to $R 32$. To verify this hypothesis, calorimetric studies were carried out.

In order to obtain information on the integral characteristics of the phase transition, the temperature dependence of the heat capacity $C_{p}(\mathrm{~T})$ was determined by calibrating the JSM signal by the dependence of the heat capacity for the reference sample (corundum). Figure 3 shows the component of heat capacity $\Delta C_{p}$, which is calculated from the relation $\Delta C_{p}=C_{p}-$ $C_{r e g}$, where $C_{r e g}$ - is the regular part of the heat capacity, obtained by approximating the temperature dependence of the total heat capacity $C_{p}(T)$ in the regions far from the phase transition area. One can see that in the region $T=504 \pm 1 \mathrm{~K}$, the temperature dependence of $\Delta C_{p}$ shows an anomaly that can be related to the proposed phase transformation $P 3_{1} 21 \rightarrow$ $R 32$, similar to phase transitions in ferroborates $\mathrm{RFe}_{3}\left(\mathrm{BO}_{3}\right)_{4}$. [8]

The magnitude of the enthalpy change during the phase transition was $\Delta H=1050 \pm 50$ $\mathrm{J} / \mathrm{mol}$. From the temperature dependence of the heat capacity $\Delta C_{p}(T)$, the enthalpy change value was determined as $\Delta S=\int(\Delta C p / T) d T$, which characterises the phase transformation at $T_{\mathrm{s}}$ $(\Delta S=2.1 \pm 0.2 \mathrm{~J} / \mathrm{mol} \cdot \mathrm{K})$. The enthalpy change $\Delta S \approx R \cdot \ln 1.3$ shows that the $R 32 \rightarrow P 3_{1} 21$ phase transition is a "bias"-type transformation and is related to structural distortions. 
To confirm that the anomaly of the temperature dependence of the heat capacity corresponds to the $P 3{ }_{1} 21 \rightarrow R 32$ phase transition, calculations from first principles were performed.

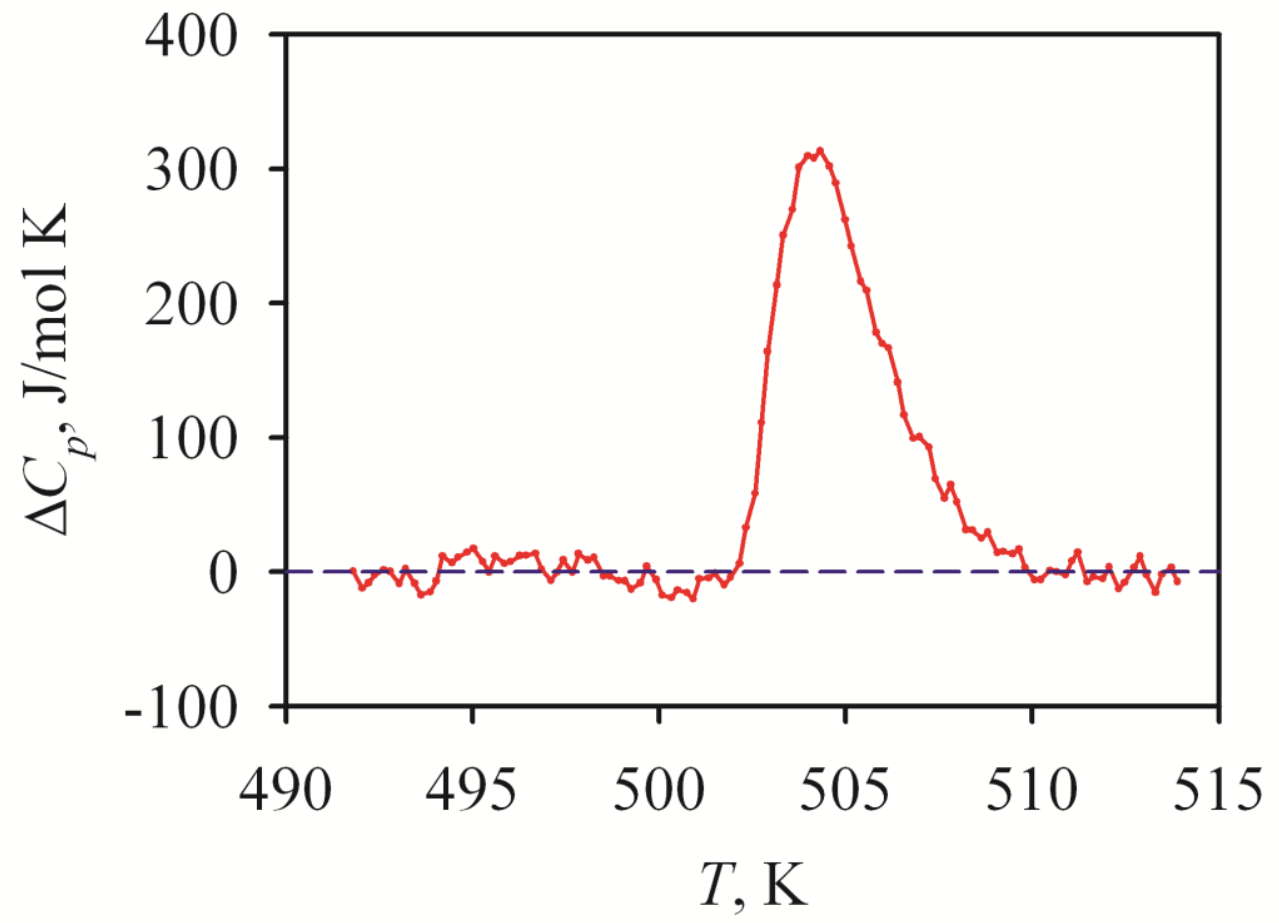

Figure 3. Temperature dependence of the excess heat capacity.

Lattice dynamics calculations were carried out using the projector-augmented wave (PAW) method [27] within density functional theory (DFT), as implemented in the VASP code. [28, 29] We used the generalised gradient approximation (GGA) functional with Perdew-BurkeErnzerhof (PBE) parametrization. [30] Electronic configurations were chosen as follows: $\mathrm{Nd}$, $5 p^{6} 5 d^{1} 6 s^{2} ;$ Sc, $3 p^{6} 3 d^{2} 4 s^{1} ; B, 2 s^{2} 2 p^{1}$; and $O, 2 s^{2} 2 p^{4}$. Nd 4f electrons were assumed as "frozen" in the core. The plane-wave cut-off was set at $600 \mathrm{eV}$. The size of the k-point mesh for Brillouin zone, based on the Monkhorst-Pack scheme, [31] was $7 \times 7 \times 7$. The phonons were calculated by constructing a supercell $(2 \times 2 \times 2)$ and calculating the force constants using the small displacement method implemented in PHONOPY. [32] 
For the $\mathrm{NdSc}_{3}\left(\mathrm{BO}_{3}\right)_{4}$ compound, the equilibrium values of the lattice parameters and atomic coordinates in phase with the structure of the huntite mineral and the $R 32$ space symmetry group were calculated, which were later used to calculate the lattice dynamics. Based on the calculation of the crystal lattice dynamics, the full phonon spectrum of the studied crystal in the $R 32$ phase was obtained (Figure 4). In this phase, the primitive cell has the form of a rhombohedron with an angle between the lattice vectors $\alpha>90^{\circ}$. For such case, the shape of the Brillouin zone and its boundary points are shown in Figure 5. The third order symmetry axis passes through $\Gamma$ and Q points, second order symmetry axis passes through $\Gamma$ and $\mathrm{F} . \Lambda$ and $\Lambda_{1}$ points are translated into each other by the second order symmetry axis. According to the results of group-theoretical analysis (see, for example, the ISOTROPY software) [33] phase transition $R 32(\mathrm{Z}=1) \rightarrow P 3{ }_{1} 21(\mathrm{Z}=3)$ is related to one component of the two-dimensional full representation $\Lambda_{3}$ (star-representation of $\Lambda_{3}$ contains two vectors $\mathbf{q}_{\Lambda}$ $=1 / 3\left(-2 \mathbf{b}_{1}+\mathbf{b}_{2}+\mathbf{b}_{3}\right)$ and $\left.\mathbf{q}_{\Lambda 1}=-1 / 3\left(-2 \mathbf{b}_{1}+\mathbf{b}_{2}+\mathbf{b}_{3}\right)\right)$.

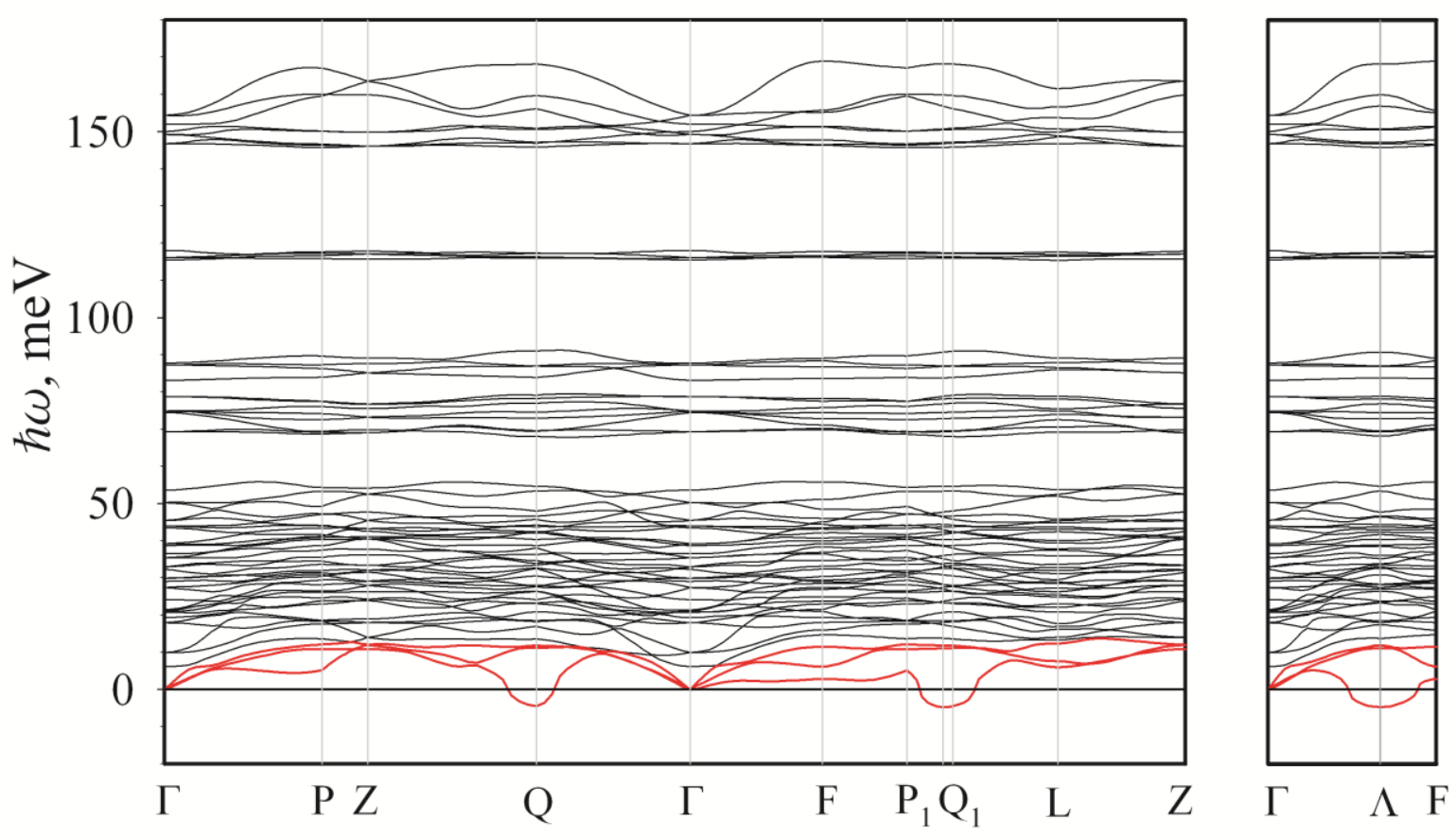


Figure 4. Theoretically calculated phonon spectrum along high-symmetry directions of the first Brillouin zone of $\mathrm{NdSc}_{3}\left(\mathrm{BO}_{3}\right)_{4}$ in the $R 32$ structure (the $\Lambda_{1}$ point is between $\mathrm{P}_{1}$ and $\mathrm{Q}_{1}$ ). Imaginary modes are shown by negative values.

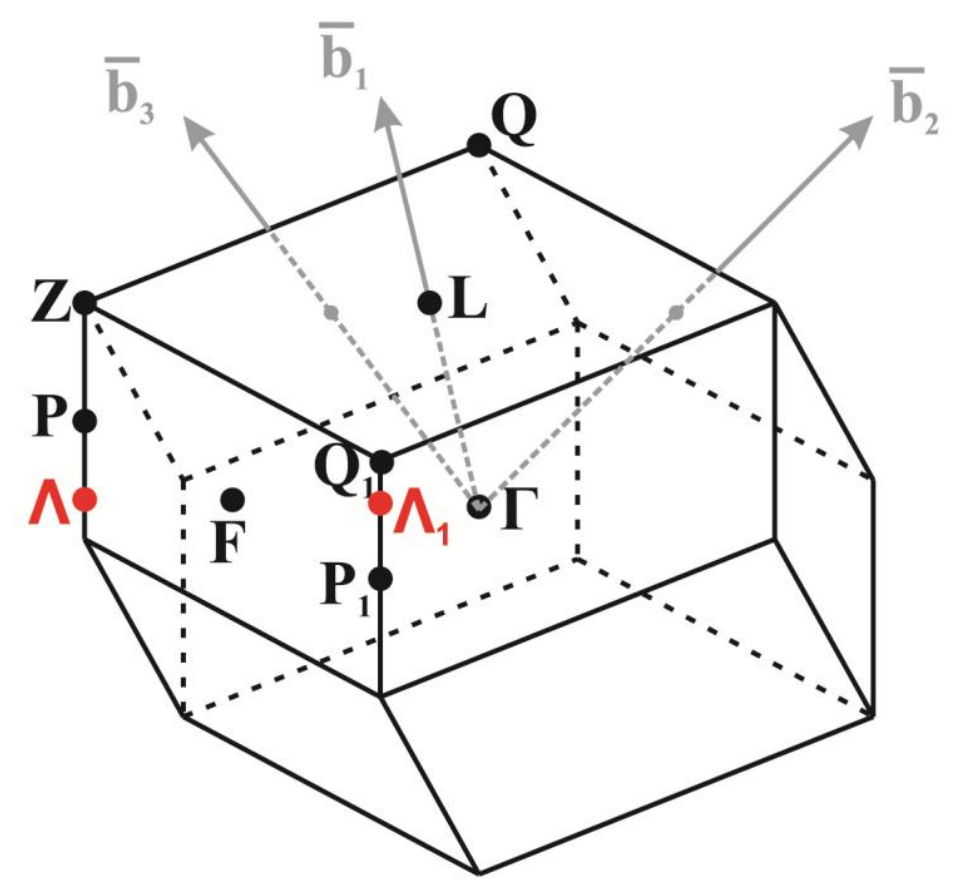

Figure 5. Brillouin zone with symmetry points and reciprocal lattice vectors of the trigonal $R 32$ symmetry group.

The obtained phonon spectrum is, at least, qualitatively similar to the previously calculated spectra for $\mathrm{RFe}_{3}\left(\mathrm{BO}_{3}\right)_{4}$ crystals. [34, 35] The main feature of the obtained spectrum is the significant deflection of the acoustic vibration branch in the vicinity of the boundary point $\Lambda$ (Figure 4). Vibrational frequencies belonging to this branch, in the nearest neighbourhood of the $\Lambda$ point take imaginary values, reaching the largest absolute value at the $\Lambda$ point itself.

In the framework of the used approach, the presence of an imaginary mode indicates the instability of the crystal lattice with respect to the structure distortion according to its own eigenvector. Indeed, the displacement of ions in the crystal under study along the eigenvector of the soft mode at the $\Lambda$ point with the corresponding tripling of the cell is energetically favourable and leads to a structure with a spatial symmetry group $P 3_{1} 21$. It is this structure 
that was observed experimentally in the present work (see above) at room temperature for an $\mathrm{NdSc}_{3}\left(\mathrm{BO}_{3}\right)_{4}$ crystal by $\mathrm{X}$-ray diffraction. The lattice parameters and relative atomic coordinates calculated from first principles, which correspond to the minimum total energy of the $\mathrm{NdSc}_{3}\left(\mathrm{BO}_{3}\right)_{4}$ crystal in the $P 3_{1} 21$ are in good agreement with the experimental data obtained (see Table 2).

\section{CONCLUSIONS}

Single crystals of rare-earth oxyborate with the huntite structure $\mathrm{NdSc}_{3}\left(\mathrm{BO}_{3}\right)_{4}$ were grown from a melt solution based on bismuth trimolybdate. The lattice parameters and the crystal structure of the grown crystal are determined by X-ray diffraction methods. It was shown that at room temperature $\mathrm{NdSc}\left(\mathrm{BO}_{3}\right)_{4}$ has the $P 3_{1} 21$ space group.

Differential scanning microcalorimetry researches showed that with increasing temperature a structural transition takes place at $\mathrm{T}=504 \pm 1 \mathrm{~K}$.

To clarify the nature of the phase transition, first principles calculations were performed within the framework of DFT. Based on the calculation of the crystal lattice dynamics, the full phonon spectrum of the investigated crystal was obtained in the $R 32$ phase. The main feature of the calculated spectrum is the significant deflection of the acoustic branch of vibrations in the vicinity of the boundary point $\Lambda$, which indicates the instability of the crystal lattice in relation to the distortion of the structure along its eigenvector. Such distortions with a corresponding tripling of the cell lead to a structure with a space group $P 3_{1} 21$. This structure was observed experimentally in the present work at room temperature for a $\mathrm{NdSc}_{3}\left(\mathrm{BO}_{3}\right)_{4}$ crystal by $\mathrm{X}$-ray analysis. The lattice parameters and relative atomic coordinates calculated from first principles, which correspond to the minimum total energy of the $\mathrm{NdSc}_{3}\left(\mathrm{BO}_{3}\right)_{4}$ crystal in the $P 3_{1} 21$ phase, are in good agreement with the experimental data obtained. 
Taking into account the data from X-ray structural analysis and calculations as well as the literature regarding phase transitions in $\mathrm{RFe}_{3}\left(\mathrm{BO}_{3}\right)_{4}$ crystals, we can assume that the anomaly in the temperature dependence of the heat capacity observed in the present work corresponds to a structural phase transition of the displacement type, from phase with the $R 32$ space group to a phase with the $P 3{ }_{1} 21$ space group.

\section{ACKNOWLEDGMENTS}

This study was supported by the Russian Foundation for Basic Research and Government of Krasnoyarsk Territory, Krasnoyarsk Region Science and Technology Support Fund by project № 18-42-240011 p_a.

\section{REFERENCES}

(1) Smolenskiü, G. A.; Chupis, I. E., Ferroelectromagnets. Soviet Physics Uspekhi 1982, 25, (7), 475 .

(2) Schmid, H., Multi-ferroic magnetoelectrics. Ferroelectrics 1994, 162, (1), 317-338.

(3) Proceedings of the MEIPIC-1, Magnetoelectric interaction phenomena in crystals.; Freeman, A. J.; Schmid H., Ed.; Gordon \& Breach Science Pub, 1975.

(4) Schmid H., Introduction to complex mediums for optics and electromagnetics. In Magnetoelectric Effects in Insulating Magnetic Materials; Weiglhofer W. S., Lakhtakia A., Ed.; - Bellingham, WA : SPIE press, 2003, 123, 167-195.

(5) Khomskii, D., Trend: Classifying multiferroics: Mechanisms and effects. Physics, 2009, $2,20-25$.

(6) Pyatakov, A. P.; Zvezdin A. K., Magnetoelectric and multiferroic media. PhysicsUspekhi, 2012, 55, (6), 593-620. 
(7) Zvezdin, A. K.; Krotov, S. S.; Kadomtseva, A. M.; Vorob’ev, G. P.; Popov, Y. F.; Pyatakov, A. P.; Bezmaternykh L. N.; Popova, E. A., Magnetoelectric effects in gadolinium iron borate $\mathrm{GdFe}_{3}\left(\mathrm{BO}_{3}\right)_{4}$., JETP Letters, 2005, 81, (6), 272-276.

(8) Kadomtseva, A. M.; Popov, Y. F.; Vorob'ev, G. P.; Pyatakov, A. P.; Krotov, S. S.; Kamilov, K. I.; Ivanov, V. Y.; Mukhin, A. A.; Zvezdin, A. K.; Kuz'menko, A. M.; Bezmaternykh, L. N.; Gudim, I. A.; Temerov, V. L., Magnetoelectric and magnetoelastic properties of rare-earth ferroborates. Low Temp. Phys., 2010, 36, (6), 511-521.

(9) Popov, A. I.; Plokhov, D. I.; Zvezdin, A. K., Quantum theory of magnetoelectricity in rare-earth multiferroics: Nd, Sm, and Eu ferroborates. Phys. Rev. B, 2013, 87, (2), 024413.

(10) Usui, T.; Tanaka, Y.; Nakajima, H.; Taguchi, M.; Chainani, A.; Oura, M.; Shin, S.; Katayama, N.; Sawa, H.; Wakabayashi, Y.; Kimura. T., Observation of quadrupole helix chirality and its domain structure in $\mathrm{DyFe}_{3}\left(\mathrm{BO}_{3}\right)_{4}$. Nature mater., 2014, 13, (6), 611-618.

(11) Demidov, A. A.; Volkov, D. V.; Gudim, I. A.; Eremin, E. V.; Boldyrev, K. N., Magnetic, magnetoelastic, and spectroscopic properties of $\mathrm{TmAl}_{3}\left(\mathrm{BO}_{3}\right)_{4}$. JETP, 2014, 119 , (4), 737-744.

(12) Begunov, A. I.; Demidov, A. A.; Gudim, I. A.; Eremin, E. V., Features of the magnetic and magnetoelectric properties of $\mathrm{HoAl}_{3}\left(\mathrm{BO}_{3}\right)_{4}$. JETP letters, 2013, 97, (9), 528-534.

(13) Volkov, N. V.; Gudim, I. A.; Eremin, E. V.; Begunov, A. I.; Demidov, A. A.; Boldyrev, K. N., Magnetization, magnetoelectric polarization, and specific heat of $\mathrm{HoGa}_{3}\left(\mathrm{BO}_{3}\right)_{4}$. JETP letters, 2014, 99, (2), 67-75.

(14) Wang, G. F. Structure, growth, nonlinear optics, and laser properties of $\mathrm{RX}_{3}\left(\mathrm{BO}_{3}\right)_{4}(\mathrm{R}$ $=\mathrm{Y}, \mathrm{Gd}, \mathrm{La} ; \mathrm{X}=\mathrm{Al}, \mathrm{Sc})$. In Structure-Property Relationships in Non-Linear Optical 
Crystals I. Structure and Bonding; Wu, X. T., Chen, L., Eds.; Springer: Berlin, 2012, 144, $105-120$.

(15) Durmanov, S. T.; Kuzmin, O. V.; Kuzmicheva, G. M.; Kutovoi, S. A.; Martynov, A. A.; Nesynov, E. K.; Panyutin, V. L.; Rudnitsky, Yu. P.; Smirnov, G. V.; Hait, V. L.; Chizhikov, V. I. Binary rare-earth scandium borates for diode-pumped lasers. Opt. Mater. 2001, 18, (2), 243-284.

(16) Huber, G. Solid-State Laser Materials. In Laser Sources and Applications; Miller, A., Finlayson, D. M., Eds.; Institute of Physics: Bristol, 1996; pp 141-162.

(17) Leonyuk, N. I.; Maltsev, V. V.; Volkova, E. A.; Pilipenko, O. V.; Koporulina, E. V.; Kisel, V. E.; Tolstik, N. A.; Kurilchik, S. V.; Kuleshov, N. V. Crystal growth and laser properties of new $\mathrm{RAl}_{3}\left(\mathrm{BO}_{3}\right)_{4}(\mathrm{R}=\mathrm{Yb}, \mathrm{Er})$ crystals. Opt. Mater., 2007, 30, (1), 161-163.

(18) Liang, K. C.; Chaudhury, R. P.; Lorenz, B.; Sun, Y. Y.; Bezmaternykh, L. N.; Temerov, V. L.; Chu, C. W., Giant magnetoelectric effect in $\mathrm{HoAl}_{3}\left(\mathrm{BO}_{3}\right)_{4}$. Phys. Rev. B, 2011, 83, (18), 180417.

(19) Chaudhury, R. P.; Lorenz, B.; Sun, Y. Y.; Bezmaternykh, L. N.; Temerov, V. L.; Chu, C. W., Magnetoelectricity and magnetostriction due to the rare-earth moment in $\mathrm{TmAl}_{3}\left(\mathrm{BO}_{3}\right)_{4}$. Phys. Rev. B, 2010, 81, (22), 220402.

(20) Liang, K. C.; Chaudhury, R. P.; Lorenz, B.; Sun, Y. Y.; Bezmaternykh, L. N.; Gudim, I. A.; Temerov, V. L.; Chu, C. W. Magnetoelectricity in the system $\mathrm{RAl}_{3}\left(\mathrm{BO}_{3}\right)_{4}(\mathrm{R}=\mathrm{Tb}, \mathrm{Ho}$, Er, Tm). J. Phys.: Conf. Ser., 2012, 400, 3, 032046.

(21) Sheldrick, G. M., A short history of SHELX. Acta Cryst., 2008, 64, (1), 112-122. 
(22) Sheldrick, G. M., Program for the refinement of crystal structures. SHELXL97. University of Göttingen, Germany, 1997.

(23) Flack, H. D., On enantiomorph-polarity estimation. Acta Cryst., 1983, 39, (6), 876881.

(24) Gorev, M. V.; Flerov, I. N.; Tressaud, A.; Bogdanov, E. V.; Kartashev, A. V.; Bayukov, O. A.; Eremin, E. V.; Krylov A.S., Heat capacity and magnetic properties of fluoride $\mathrm{CsFe}_{2} \mathrm{Fe}_{3} \mathrm{~F}_{6}$ with defect pyrochlore structure. J. Solid State Chem., 2016, 237, 330335.

(25) Klimin, S. A.; Fausti, D.; Meetsma, A.; Bezmaternykh, L. N.; van Loosdrecht, P. H. M.; Palstra, T. T. M., Evidence for differentiation in the iron-helicoidal chain in $\mathrm{GdFe}_{3}\left(\mathrm{BO}_{3}\right)_{4}$. Acta Cryst.. 2005, B61, 481-485.

(26) Kuz'micheva, G. M.; Kaurova, I. A.; Rybakov, V. B.; Podbel'sky, V. V.; Chuykin. N. K., Structural Instability in Single-Crystal Rare-Earth Scandium Borates $\mathrm{ReSc}_{3}\left(\mathrm{BO}_{3}\right)_{4}$. Cryst. Growth Des., 2018, 18, 1571-1580.

(27) Kresse, G.; Joubert, D., From ultrasoft pseudopotentials to the projector augmentedwave method. Phys. Rev. B, 1999, 59, 1758.

(28) Kresse, G.; Furthmüller, J., Efficient iterative schemes for ab initio total-energy calculations using a plane-wave basis set. Phys. Rev. B, 1996, 54, 11169.

(29) Kresse, G.; Furthmüller, J., Efficiency of ab-initio total energy calculations for metals and semiconductors using a plane-wave basis set. Comput. Phys. Sci., 1996, 6, 15.

(30) Perdew, J. P.; Burke, K.; Ernzerhof, M., Generalized Gradient Approximation Made Simple. Phys. Rev. Lett., 1996, 77, 3865. 
(31) Monkhorst, H. J.; Pack, J. D., Special points for Brillouin-zone integrations. Phys. Rev. $B, \mathbf{1 9 7 6}, 13,5188$.

(32) Togo, A.; Tanaka, T.; First principles phonon calculations in materials science. Scr. Mater., 2015, 108, 1.

(33) ISOTROPY Software Suite [http://iso.byu.edu]

(34) Pavlovskiy, M. S.; Shaykhutdinov, K. A.; Wu, L. S.; Ehlers, G.; Temerov, V. L.; Gudim, I. A.; Shinkorenko, A. S.; Podlesnyak, A., Observation of soft phonon mode in $\mathrm{TbFe}_{3}\left(\mathrm{BO}_{3}\right)_{4}$ by inelastic neutron scattering. Phys. Rev. B, 2018, 97, (5), 054313.

(35) Pavlovskiy, M. S.; Zinenko, V. I.; Shinkorenko, A. S., Effect of a Rare-Earth Ion on the Structural Instability in $\mathrm{RFe}_{3}\left(\mathrm{BO}_{3}\right)_{4}$ Crystals. JETP Letters, 2018, 108, (2), 116-120. 


\section{Highlights}

- High quality single crystals of $\mathrm{NdSc}_{3}\left(\mathrm{BO}_{3}\right)_{4}$ were grown from melt-solution.

- Structural instability responsible for phase transition $R 32 \rightarrow P 3{ }_{1} 21$ was found from DFT.

- Temperature of transition was obtained from anomaly heat capacity measurements.

- Structure of low temperature phase was determined by X-ray diffraction methods. 